\title{
El primer fracaso económico de la nueva era democrática: Argentina entre la crisis y la transición democrática $(1983-1985)^{1}$
}

O primeiro fracasso econômico da nova era democrática: a Argentina entre a crise e a transição democrática (19831985)

The first economic failure of the new democratic era: Argentina between the crisis and the democratic transition (19831985)

Ignacio Rossi

ignacio.a.rossi@outlook.com

Universidad Nacional General Sarmiento - Argentina

https://orcid.org/0000-0003-3870-1630

\begin{abstract}
RESUMEN
Proponemos un abordaje crítico del primer programa económico del gobierno de transición democrática de Raúl Alfonsín (1983-1989) en Argentina. En un contexto de crisis económica nacional tras el legado de una dictadura precedente (1976-1983) combinada con la crisis de la deuda latinoamericana a partir de 1982, el ministro de economía Bernardo Grinspun (1983-1985) propuso un programa económico keynesiano en sintonía con los aires del primer gobierno democrático de una nueva era. En este marco, revisamos las principales discusiones económicas de la época como algunos testimonios con el fin de realizar una interpretación completa sobre los alicientes de dicho plan, su desarrollo y posterior fracaso. Hemos constatado que el programa de Grinspun constituyó el último plan keynesiano desde la hegemonía de posguerra, que se asentó en raíces históricas y que los cambios ocurridos en la economía desde la dictadura de 1976 como el creciente poder económico local y extranjero jaquearon su desarrollo aislando al gobierno democrático.
\end{abstract}

Palabras clave: democracia; economía; deuda; empresarios; Argentina.

\section{RESUMO}

Propomos uma abordagem crítica ao primeiro programa econômico do governo de transição democrática de Raúl Alfonsín (1983-1989) na Argentina. Num contexto de crise económica nacional a partir do legado de uma ditadura anterior (1976-1983) aliada à crise da dívida latino-americana de $1982 \mathrm{em}$ diante, o Ministro da Economia Bernardo Grinspun (1983-1985) propôs um programa económico keynesiano em sintonia com a ares do primeiro governo democrático de uma nova era. Neste quadro, revemos as principais discussões económicas da época como alguns testemunhos de forma a fazer uma interpretação completa dos incentivos do referido plano, do seu desenvolvimento e consequente insucesso. Verificamos que o programa Grinspun constituiu o último plano keynesiano desde a hegemonia do pós-guerra, que se baseava em raízes históricas e que as mudanças ocorridas na economia desde a ditadura de 1976 com o crescimento do poder econômico local e estrangeiro dificultaram seu desenvolvimento ao isolar os governos democráticos.

Palavras-chave: democracia; economia; dívida; empresários; Argentina.

\section{ABSTRACT}

We propose a critical approach to the first economic program of the democratic transition government of Raúl Alfonsín (1983-1989) in Argentina. In a context of national economic crisis after the legacy of a preceding dictatorship (19761983) combined with the Latin American debt crisis from 1982 onwards, the Minister of Economy Bernardo Grinspun (1983-1985) proposed a Keynesian economic program in tune with the airs of the first democratic government of a new era. In this framework, we review the main economic discussions of the time as some testimonies in order to make a complete interpretation of the incentives of said plan, its development and subsequent failure. We have verified that the Grinspun program constituted the last Keynesian plan since the postwar hegemony, which was based on historical roots and that the changes that occurred in the economy since the 1976 dictatorship as the growing local and foreign economic power hampered its development by isolating the democratic government.

1 Quisiera dar mis agradecimientos y eximir de todas mis omisiones y errores en este trabajo a la economista Dra. María Karina Forcinito y el historiador Dr. Andrés Martín Regalsky por contribuir con mi dirección y formación de maestría y doctorado. 
Keywords: democracy; economy; debt; businessmen. Argentina.

\section{INTRODUCCIÓN}

Este trabajo debe ser entendido en el contexto de la transición democrática argentina desarrollado por la presidencia de Alfonsín. El devenir de dicho proceso resultó ampliamente condicionado en el aspecto económico por un contexto de fuertes restricciones externas causadas por la enorme deuda pública, la caída de los términos de intercambio y la creciente influencia de organismos internacionales para presionar por los intereses de dicha deuda. En la economía nacional, además de los problemas económicos, se tornaban significativos los poderes económicos locales y otros consolidados tras la dictadura con gran capacidad de influencia en las redes más o menos formales de gobierno. ${ }^{2}$ En este marco, encarar la construcción de un régimen democrático con una arquitectura que trascendiera la mera celebración de elecciones y un presidencialismo condicionado se tornó una tarea compleja para la fuerza política que asumía tras una larga dictadura (1976-1983). Los debates económicos en aquellos años se encontraban atravesados por las controversias de una crisis del modelo de acumulación argentino, puntualmente de si la violenta liberalización y desregulación en varias áreas de la economía que había realizado el régimen dictatorial anterior había iniciado una etapa de reestructuración capitalista o si había sido solo un ajuste liberal ortodoxo (Bonnet y Piva, 2019). Esto en gran medida puede entenderse a la luz de la errática política económica del alfonsinismo, que ensayara desde una reactivación neo-keynesiana hasta políticas progresivamente ortodoxas en concertación con instituciones financieras, pero sin poder realizar una integración a la economía mundial sino hasta el gobierno de Carlos Menem (1989-1999) que inaugurara la década neoliberal en nuestro país.

El régimen dictatorial anterior se caracterizó por un programa liberalizador y desregulador que se inscribía en el fin de la hegemonía del ideario que sustentaron las fases de la Industrialización por Sustitución de Importaciones (ISI) desde la posguerra (Rougier y Odisio, 2018). Este plan, llevado a cabo en el sector comercial, de precios, financiero, etc., sufrió un golpe de gracia con la crisis de la deuda de 1982 desatada tras la mora mexicana. Con dichos antecedentes, el panorama económico para la Unión Cívica Radical (UCR) de Alfonsín en diciembre de 1983 se tornaba sombrío: un endeudamiento externo de 46.200 millones de dólares (equivalente a casi el $70 \%$ del PBI), un déficit público de casi 15 puntos del PBI, una economía en recesión al menos desde la crisis financiera de $1982,{ }^{3}$ creciente desocupación, una inflación de más del $400 \%$ y endebles reservas internacionales calculadas en 100 millones de dólares (Rapoport, 2020a). En un comienzo el gobierno, más preocupado por restablecer la institucionalidad y la democratización social tras años de proscripción, desapariciones y censuras, mostró poca importancia a las cuestiones económicas, que también eran desfavorables en un contexto internacional de proteccionismo europeo, caída de los términos de intercambios y altas tasas de

2 Nos referimos, específicamente a aquel sector del empresariado con mayor capacidad de lobby, como los que se organizaban formalmente en la Unión Industrial Argentina (UIA), la Confederación General de la Industria (CGI), el Consejo Argentino de la Industria (CIA), la Sociedad Rural Argentina (SRA), la Federación Agraria Argentina (FAA), la Cámara Argentina de la Construcción (CAC), la Asociación de Bancos de la República Argentina (ABRA), la Bolsa de Comercio de Buenos Aires (BCBA) entre otras, y los de organización informal como el Consejo Empresario Argentino y los llamados Capitanes de la Industria que se vinculaban con el Estado por fuera de la lógica corporativa (Beltrán, 2006).

3 Una reforma de carácter liberalizador en el sistema financiera llevada a cabo en 1977 dejaba al gobierno democrático un sistema financiero de gran fragilidad (Heymann, 1986) que perdió su capacidad de regular el mercado financiero y dejó la expansión paralela de las actividades financieras y la descentralización de los depósitos. Así, las actividades regulares de crédito se reemplazaron por inversiones especulativas donde las empresas no financieras comenzaron a concentrar sus ganancias en colocaciones financieras en un contexto de reducción de plazos mínimos y elevadas tasas de interés. Finalmente cabe mencionar que el Banco Central garantizaba los depósitos del sistema lo que significaba que ante la quiebra de una entidad debía devolverlos. A partir de aquí es que puede entenderse la herencia en materia financiera del alfonsinismo, especialmente el déficit cuasi fiscal del que se comenzaba a hablar en aquel entonces y un sistema financiero que iba a contracorriente de cualquier orientación productiva con impacto en el empleo (Barón Lajer, 2018). 
interés impulsadas por la política antiinflacionaria estadounidense (Rapoport, 2020b; Escudé y Cisneros, 2000).

El plan Grinspun, que entendemos como el primer fracaso económico de la era democrática, marcó un punto de inflexión para el errático avance de la ortodoxia económica ligada a las ideas neoliberales de aquel entonces. Sin embargo, la primera estrategia económica del gobierno democrático ha sido escasamente abordada, por lo que proponemos aquí un examen exhaustivo de sus propuestas, su base partidaria, sus condicionantes como la evolución de la misma hasta el giro económico producido a partir de 1985 con el fin de interpretar qué significó su fracaso. De antemano, se entiende que la coyuntura económica de la década de 1980 asistía a una redefinición del capitalismo global que en América Latina se caracterizaba por la crisis de la deuda. No obstante, el equipo económico de aquel entonces tuvo un diagnóstico positivo de dicha coyuntura, lo que lo llevó a confrontar con actores internacionales y poderes locales, debiendo finalmente que desistir ante las presiones de diversos actores de poder. De esta forma, proponemos describir y reflexionar en torno a los problemas económicos más acuciantes que jaquearon la propuesta económica neokeynesiana, la última de hecho, de cara al consenso neoliberal y la aceptación de los cánones ortodoxos clásicos.

\section{FUNDAMENTACIÓN TEÓRICA Y BREVE ESTADO DEL ARTE}

En este cuadro el primer equipo económico del alfonsinismo cumplió un papel que reflejó los cambios de la época y cómo las antiguas recetas tanto neokeynesianas como ortodoxas resultaban difícilmente practicables en el nuevo contexto; desembocando en crecientes ansias de estabilidad económica y la posibilidad de realizar reformas de fondo para sortear la crisis que identificaban crecientemente al Estado como el principal causante de la ineficiencia, el endeudamiento, el déficit públicos y la inflación (Fair, 2013).

Una línea de estudios sobre la historia económica Argentina sostiene que, a partir de la dictadura militar, se desató una crisis en el régimen de acumulación, aunque no es hegemónica esta interpretación, dado que otros sostienen que desde la posguerra los mecanismos institucionales de desarrollo económicos eran deficientes (Díaz Alejandro, 1975; Lewis, 1993). En línea con la primera visión, entendemos que en el último cuarto del siglo XX se consolidó un sistema de valorización financiera y el abandono del modelo de ISI que caracterizó al país en las décadas previas (Basualdo, 2018). Por otro lado, y según la Teoría de la Regulación en la que destacan los trabajos de Miotti (1991) y Neffa (1998), la crisis del régimen de acumulación puso en jaque al modelo de desarrollo en su conjunto. A partir de entonces, las regularidades más esenciales de un sistema económico como la organización de la producción, la distribución del ingreso y la demanda social se encontraban atravesando un malfuncionamiento.

Panigo y Zane (2004), identifican como causas de la crisis la incompatibilidad entre las inversiones basadas en la tasa de beneficios, una relación salarial competitiva (mediante la supresión de actividades sindicales) y la caída de las ventas determinadas por la demanda doméstica. Por otra parte, deben agregarse las formas de competencia oligopólicas en un contexto de apertura comercial y financiera con un tipo de cambio administrado que incentivaban un aumento de precios. En este marco, las reglas de comportamiento del pasado no encontraban sustento económico social y se encaminaba a un punto de ruptura que desató una crisis. Como dice Miotti (1991), retomando el concepto de crisis estructural de Boyer (1992), se cumplía la ausencia de una recuperación endógena de la actividad económica, se desata la destrucción del modo de regulación vigente (traducida en la transformación del sistema financiero) y las anticipaciones macroeconómicas, es decir expectativas, se muestran ineficientes.

Teniendo en cuenta esto, debemos entender el difícil desenvolvimiento que le esperaba al gobierno de Alfonsín, más preocupado por la institucionalidad y la democratización social, y a su 
primer equipo económico. Esta primera estrategia económica, aunque poco abordada de forma directa por las ciencias sociales, cuenta con varios trabajos de referencia. Por un lado, existe la producción contemporánea que se han preocupado por los problemas económicos durante el gobierno de Alfonsín. Esta, discutió los problemas estructurales de la economía argentina como la inflación, el endeudamiento, la fuga de capitales y los shocks externos, entre otras cuestiones ( Heymann, 1986; Frenkel y Fanelli, 1986 ; Schvarzer, 1987a,b; Dornbusch y Simonsen, 1987; Damill, Fanelli, Frenkel y Rozenwurcel, 1989). Sin embargo, fue menos la atención que recibió la primera estrategia económica del gobierno tanto desde los estudios económicos contemporáneos como de los sociales posteriormente. Claro que manuales, ya clásicos y reeditados recientemente, de historia económica argentina lo incluyen y desarrollan en sus características por intentar reimpulsar el crecimiento económico a partir de medidas antinflacionarias como los acuerdos de precios y salarios; el aumento de ingresos tributarios a partir de un mayor control a la evasión y de suba de impuestos a los ingresos y la riqueza. También se incentivó la expansión de la demanda interna a partir de la reducción del costo del crédito, el control del gasto público y el incremento de los salarios y de la reactivación a través el aprovechamiento de la capacidad ociosa (Gerchunoff y Llach, 2019; Rapoport, 2020; Belini y Korol, 2020).

Más particularmente existe una línea de estudios económicos provenientes de la heterodoxia de la escuela de la Facultad Latinoamericana de Ciencias Sociales (FLACSO), como los de (Azpiazu, 1991; Canitrot, 1992; Ossona, 1992; Azpiazu, Basualdo y Khavisse, 2004) que entienden que existió una fuerte continuidad con la etapa dictatorial, en tanto no se desmontaron las prácticas financieras cortoplacistas como la continuidad de seguros de cambio que hicieron posible la estatización de parte de la deuda privada sin investigación previa, los subsidios a sectores concentrados de la economía mediante la continuidad de los regímenes de promoción industrial, regional y sectorial y la caída del salario real de los asalariados. En una similar, retomando sus principales propuestas y centrándose en el cambio de un modo de acumulación de industrialización por sustitución de importaciones a uno de valorización financiera, aunque a través de actores específicos como los empresarios, las alianzas políticas, prosiguieron los trabajos de (Pesce, 2006; Castellani, 2006; Aruguete, 2006). En este contexto, los trabajos señalados entienden que se desconocían los cambios estructurales que se habían producido como consecuencia de la política de la dictadura. De la misma forma destaca la legitimación de las ideas neoliberales a lo largo de la década, principalmente a través de centros profesionales y corporaciones empresariales (Beltrán, 2006) como desde la participación de economistas y técnicos extrapartidarios en la política y su incidencia ideológica para legitimar el repertorio neoliberal (Heredia, 2006). Estos comenzaron a aceptar los postulados internacionales que, a nivel doméstico, ganaban terreno ofreciendo un diagnóstico sencillo y aglutinante para los sectores dominantes consolidados durante los años de dictadura que responsabilizaba al Estado de las sucesivas crisis. En general, este último conjunto de aportes adhiere a la idea general de que el alfonsinismo constituyó una plataforma política de continuidad entre la dictadura y el auge de la década neoliberal en los años 1990 en tanto no se generaron cambios de envergadura en la estructura económica nacional que se encontraba entre una ambivalencia entre los poderes concentrados locales y los actores internacionales (Ortiz y Schorr, 2006).

Además, estos trabajos analizan históricamente los cambios en el patrón de acumulación a partir de las amplias transformaciones producidas en el modelo de ISI durante la dictadura militar y su correlato en la consolidación de fracciones del capital concentrado local y extranjero que, en relaciones privilegiadas con el Estado, consolidó un significativo poder en los años 1980. Incluso, algunos de estos trabajos incorporan al análisis aportes de la corriente marxista-estructuralista poulantziana y gramsciana o neoinstitucionalista para explicar esos cambios (Acuña y Golbert, 1990; Azpiazu y Nochteff, 1996; Boyer y Neffa, 2004; Aronskind, 2008; Basualdo, 2018) y otros enfatizaron en el análisis del discurso político de los ministros de economía (Muraca, 2007). 


\section{PROCEDIMIENTOS METODOLÓGICOS}

Si bien el presente artículo tiene un carácter más cercano a la revisión bibliográfica e interpretativa de raíz histórica que a la heurística, adherimos a un conjunto de procedimientos metodológicos de carácter estrictamente cualitativos. En este sentido, nos ceñimos a la observación de la propuesta económica y política de Grinspun, a su relación con el contexto democrático, la evolución del mismo en términos económicos y a sus limitaciones posteriores hasta su fracaso. De acuerdo a una propuesta historiográfica interdisciplinaria con la politología y la economía, realizamos un abordaje histórico del primer plan económico alfonsinista recurriendo a la producción intelectual de la época, estudios posteriores y pronunciamientos oficiales. De este modo, se consultan discursos oficiales y estadísticas relevantes que nos permiten realizar una reconstrucción de acuerdo a los objetivos del trabajo. Con respecto a los criterios de análisis historiográfico adoptado hemos adherido a un conjunto de técnicas del análisis del discurso que describimos a continuación.

Seguimos a Angenot (2010), quien teorizó sobre la dimensión hegemonía del discurso, como de los componentes de una división del trabajo discursivo, que nos han funcionado como variables para nuestra observación. En línea con su análisis, nos ha resultado especialmente importante la imposición de los tabúes en el discurso, entendidos estos como algo intocable, de los que habla el autor mencionado. Estos funcionaban en el discurso de la política económica como artefactos que permitían la legitimación del Estado nacional, especialmente frente a los poderes extranjeros, y que solventaban la estrategia keynesiana en el nuevo contexto post dictatorial: la defensa de la patria, la reivindicación de la independencia financiera, del papel del Estado en la producción y del salario real, por mencionar algunos. En la misma línea, también los componentes egocentristas de la hegemonía resultan útiles para interpretar cómo el discurso neokeynesiano que desplegaban el presidente y Grinspun permitía izar la bandera democrática en la defensa del pueblo y más específicamente en favor de la civilidad que los apoyaba, aunque en el plano de la realidad las tensiones postautoritarias fueran importantes sea con el gremialismo, las empresas, la oposición política, etc. Es de esta forma que el concepto de hegemonía se muestra importante para analizar el momento alfonsinista que transcurrió a partir de 1983 con el apoyo electoral y civil que le permitió, en definitiva, tras una salida de facto de la dictadura de 1976, consolidar con cierta independencia su programa económico.

Por otra parte, también creemos que es importante la categoría de representación social según Van Dijk (1999) que señala que los aspectos sociales de un evento comunicativo se encuentran controlados por representaciones sociales de los mismos participantes, o lo que es lo mismo, por una lectura social de los enunciantes. Esto permite ciertamente no ser tan específico acerca de las posibilidades de los supuestos consolidados, incluso contemporáneamente, como el avance democrático, la concertación de precios, la denuncia contra la ilegitimidad de la deuda externa, entre otras cosas. Sino mas bien que el discurso desplegado por los enunciantes debe ser entendido en su contexto sociopolítico observando a los actores que los sustentan y a los que efectivamente se les enuncia dicho discurso. También, Van Dijk (1999) entiende que los dominios ideológicos son sitios de dominación, lucha, conflictos e intereses. Esto se tornaría fundamental si consideramos que, a través de la recuperación de cierta unidad latinoamericana para discutir el problema de la deuda externa, la apelación a una unidad democrática continental contra las dictaduras como de las condicionalidades que imponía el FMI, entre otras cosas, eran incluidas en el discurso como componentes de los conflictos de intereses y las luchas que abrían las postdictaduras. En este sentido, por momentos existía un desplazamiento discursivo que ayudaba a narrar cierto "punto ciego de la experiencia" (Piglia, 2013: 3) en tanto era al pueblo argentino a quien se le narran las soluciones ante el imperialismo.4Aunque también, a su vez, podemos detectar

${ }^{4}$ No es que aquí la táctica sea, como en el texto de Piglia (2013) en función de un acontecimiento imposible de narrar, sino que, por el contrario, al tratarse de un contexto sociopolítico y enunciativo diferente podría decirse que Alfonsín desplaza la responsabilidad cívica a la ciudadanía en su conjunto donde presenta al partido como un actor más en la transición. 
de acuerdo con Van Dijk (1999) una ejecución de la comunicación ligada a los intereses mediante una posición estratégica que remitía a la existencia de una crisis económica solucionable con las herramientas de antaño.

También, adicionalmente se podría mencionar, si seguimos la línea discursiva desde el punto de vista de la sociología de Bourdieu (1985), que podemos interpretar cómo concepciones referentes a la justicia social y al pueblo, tradicionalmente envalentonadas por el peronismo, pero en estos años extendidas y disputadas por el radicalismo alfonsinista, se volvían un espacio de lucha por la apropiación. Esta disputa podría inscribirse, a su vez, como parte de una práctica social condicionada por un nivel material donde se presentaba al dilema de aumentar la intervención del Estado en la postdictadura (democratización, economía política, etc.) en beneficio del pueblo frente a el contrapeso de nuevos actores de poder que replanteaban la escena en función de cómo se venían desarrollando las estrategias de los Estados.

En suma, hasta aquí resulta claro que un análisis discursivo, que subraye el carácter de acción del mismo (Fairclough y Wodak, 2000), como una práctica social contextualizada, permitirá observar en un sentido amplio el contexto condicionante de ese discurso. A saber, en el plano discursivo un conjunto de prácticas consideradas nocivas, especialmente por el alfonsinismo, como el endeudamiento, la búsqueda de beneficios vinculado al Estado y en general las formas corporativas, eran encasilladas como los males económicos y político del momento. Pero también, por otro lado, existían aspectos socioculturales que remitían a valores inscriptos en la libertad individual y que, en gran medida, determinaban que las soluciones a los males mencionados dependían de cada uno: el pueblo debe ser responsable y asumir una actitud comprometida con la democracia. Aunque a pesar de la dimensión situacional, "es la construcción personal de esos criterios de relevancia la que, para cada discurso, ejerce la restricción real del texto" (Van Dijk, 1999: 270). Pero también podríamos agregar la observación de cómo en el plano semánticodiscursivo se apuntaba a emociones concretas como forma de interpelar a los actores: la agresividad de las empresas extranjeras a costa del sufrimiento del pueblo, pero a su vez, el pueblo debe sacrificarse, si el Estado responde como se espera (enfrentándose al imperialismo mediante el apoyo a la institucionalidad, podríamos decir). Quizás aquí puedan observarse dos tipos de roles comunicativos (Van Dijk, 1999): el profesional y el social. En cuanto al primero se entiende que el acto comunicativo se encuentra definido en gran medida desde un rol profesional: el funcionario, el presidente del BCRA, el parlamento o el gobierno, quienes definían la viabilidad de la institucionalidad democrática. Por otro lado, lo social, sería definido en gran medida por la capacidad de hablar como un amigo, un defensor, en este caso con capacidad de convencer: la democracia nos interpela para no volver a repetir un pasado indeseado por todos.

\section{EL EQUIPO ECONÓMICO FRENTE A LA TRANSICIÓN DEMOCRÁTICA}

El ministro Grinspun estuvo al frente de la cartera económica del gobierno democrático durante el primer año de la gestión radical. En general, su programa se propuso lograr un crecimiento del 5\% del PBI anual, acordar con los acreedores según la capacidad de pago del país, aumentar los salarios reales en un $8 \%$, bajar la inflación mediante una concertación de precios y aumentar los ingresos tributarios evitando la evasión fiscal y fijando mayores impuestos sobre la riqueza (Rapoport, 2020). En esta visión, lograr el crecimiento económico, distribuir y controlar la inflación, no aparecían como lógicas contradictorias, sino más bien como causas y consecuencias de un proceso que podía reimpulsarse con escasos consensos (De Riz y Feldman, 1991).

Específicamente Grinspun había formado parte del equipo económico del presidente Arturo Illia (1963-1966), caracterizada por el empleo de los típicos instrumentos macroeconómicos de corto plazo de la política económica keynesiana: principalmente, expansión fiscal desde aumentos en las compras del Estado y estímulos al crédito vía emisión monetaria. Este grupo de expertos se caracterizaban por mantenerse al margen de las disputas partidarias y haber manejado, en aquel 
entonces, con cierto éxito el desarrollo económico. Grinspun fue secretario del Consejo Nacional de Desarrollo, presidente del Banco Central (BCRA), Secretario de Comercio entre 1963-1966 y junto a Alfonsín formó parte del Movimiento de Renovación y Cambio, como muchos otros funcionarios de la UCR. Entre estos últimos, cabe mencionar a Enrique García Vázquez, quien ocupara el cargo de presidente del BCRA (1983-1985 y 1989) y había formado parte del gobierno de Illia como vicepresidente del mismo banco (1963-1966). También Roque Carranza, un ingeniero radical de raíz desarrollista que formó parte del gobierno de Arturo Illia como Secretario Técnico de la Comisión Nacional de Desarrollo (1963-1966) y durante la gestión radical de 1983 ocupó el cargo de Ministro de Obras y Servicios Públicos (1983-1985). El químico radical Germán López, por su parte, que había ocupado el cargo de Subsecretario de Trabajo en la gestión Illia, se desempeñó en 1983 como Secretario General de la Presidencia con activa participación en la política sindical y luego fue nombrado como Ministro de Defensa 1986. Raúl Borrás fue subsecretario de Agricultura (1984), jefe de campaña de Alfonsín (1983) y Ministro de Defensa (1985). El economista Alfredo Concepción había sido Secretario de Comercio de la Nación entre 1963-66, presidente del Banco de la Nación Argentina en 1984, Secretario de Comercio del Interior (1984-85) y presidente del BCRA (1985-86). Como afirmara De Riz y Feldman (1991), “todos ellos tenían su gabinete, con tradición partidaria, fieles a la autoridad de sus jefes y nucleados en un proyecto keynesiano de reconstrucción de la infraestructura pública, como condición de un Estado fuerte, capaz de generar demanda y sentar las bases del desarrollo económico" (8).

El nuevo equipo, diagnosticaba que el problema principal de la economía se originaba en los altos niveles de desocupación y los bajos salarios heredados de la dictadura (Pesce, 2006). Ambos indicadores provocaban una caída abrupta de la demanda y una retracción de la producción, por lo que había que concentrar los esfuerzos en la capacidad industrial ociosa y del mercado interno combinada con una mayor recaudación impositiva que permitiera reducir el déficit fiscal. En el peor de los casos, el equipo entendía que se produciría un crecimiento con inflación originado en una inevitable emisión monetaria. La intención era ordenar el sector externo y desacelerar la inflación incentivando la modernización económica y las inversiones. En este programa, el salario real y el empleo, tenían un lugar prioritario, ya que los sectores asalariados que habían perdido participación en el ingreso durante la dictadura (Azpiazu, Basualdo y Khavisse, 2004) debían beneficiarse de la reactivación de la demanda.

Alfonsín había previsto esta línea en su campaña afirmando que la política económica se sustentaría en la reactivación de la demanda agregada, el aumento de la producción y la recuperación de las capacidades del BCRA. Todo esto se dirigiría contra la herencia de la dictadura en torno a la especulación financiera. Así lo decía al momento de su asunción:

\footnotetext{
"Vamos a aumentar el poder de compra del pueblo, esto aumentará la demanda efectiva, el aumento de la demanda generará la necesidad de aumentar la producción, y para aumentar la producción habrá que tomar nuevos empleados y así vamos a poner en marcha el aparato productivo de la Nación. Pero hay una sola forma de lograr de entrada un aumento en serio del poder de compra del salario real -no del salario nominal, que al día siguiente es absorbido por el aumento de precios-: terminar con el actual sistema financiero. Se acaba la usura oficializada en la Argentina. ¡Se acaba la patria financiera! El Banco Central decidirá las tasas de interés, orientará el crédito, determinará líneas de redescuento y créditos preferenciales, pero se acabó con la usura en el país". 5
}

Por su parte, Grinspun decía que "La concentración de poder político y de recursos en lo que se denominó la 'patria financiera' favoreció ganancias fáciles para un grupo privilegiado, difundiendo un espejismo entre sectores sociales que dejaron de lado las actividades productivas". ${ }^{6}$

Sin embargo, objetivamente se encontraba el problema de la deuda y el hostil contexto externo comercial y financiero que imponía severas restricciones a la política económica en el ámbito externo. No obstante, y como hemos visto, había un optimismo por parte del gobierno

5 Raúl Alfonsín (30 de septiembre de 1983) Discurso de campaña en el estadio del Club Ferrocarril Oeste. Recuperado de: https://www.alfonsin.org/wp-content/uploads/2019/02/Discurso_de_campana-en_el_estadio_del_ClubFerrocarrilOeste.pdf

6 Grinspun Bernardo, Discurso pronunciado por Cadena Nacional de Radio y Televisión. 19 de Julio de 1984. Centro de Documentación e Información, Ministerio de Economía, Buenos Aires, p. 4-5. 
democrático en que las condiciones de la negociación externa con los acreedores internacionales se tornarían favorables para las renacientes democracias. Un optimismo fundado en la voluntad de los acreedores, en el gobierno de los EE. UU y los países desarrollados ansiosos en apoyar a las democracias latinoamericanas (Escudé, 2006). Así lo señalaba Alfonsín en 1983:

\begin{abstract}
"Vamos a pagar la deuda en la medida de nuestras exportaciones, y es por eso que vamos a reclamar la solidaridad de todas las democracias del mundo, para que se comprenda que quienes fueron temerarios durante la dictadura al emprender una política que significó sembrar créditos al voleo y a cualquier interés no podrán exigir a la democracia, frente a la necesidad de aumentar su crecimiento de la economía, frente a la necesidad de dar satisfacción a requerimientos elementales del pueblo; no podrán exigir que se paguen intereses como ahora, en estos contratos de refinanciación de la deuda de Aerolíneas Argentinas de más del 10\% de la inflación. Vamos a aumentar la producción, y en todas las actividades"?
\end{abstract}

La postura crítica al respecto, también era compartida por Grinspun, que decía que "la deuda externa [constituye un] enorme endeudamiento [que] no fue utilizado para capitalizar al país sino para destruirlo [y donde] el sistema financiero [fue] transformado en un mecanismo para favorecer la especulación, en vez de las actividades productivas". 8

El equipo económico estaba convencido de que la deuda no constituía un problema financiero, sino más bien uno de carácter político (Schvarzer, 1997b). En esta línea, se intentó una negociación directa con los acreedores, evitando pasar por el FMI, exigiendo que se supeditaran los pagos al crecimiento del país entre un 10-15 de las exportaciones. Esta postura fue rechazada, tanto por los acreedores como por los gobiernos centrales, aunque los esfuerzos del equipo económico no se agotaron y contra las recomendaciones del entonces asesor presidencial Raúl Prébisch, se optó por regionalizar el problema buscando relaciones con otros países latinoamericanos endeudados. Así se desarrolló, con la participación del ministro de Relaciones Exteriores Dante Caputo y con la presencia de Brasil, Colombia y México, la convocatoria a una reunión de cancilleres y ministros de economías de países endeudados con el fin de presionar por cambios en la política financiera y comercial internacional. Al poco tiempo, los países mencionados junto a Ecuador, Perú y Venezuela, redactaron un documento solicitando un dialogo con el Grupo de los Siete (G7) para aliviar la carga de la deuda externa. Sin embargo, los mandatarios de los países industrializados insistieron en encarar el problema de la deuda de forma bilateral. Por consiguiente, se realizó en junio de ese año el Consenso de Cartagena, ${ }^{9}$ en el que se reunían once naciones latinoamericanas de los países deudores de la región con el fin de reclamar a los acreedores mejores condiciones de renegociación de la deuda frente al problema que causaban el alza de las altas tasas de interés internacionales y reclamaban, en un sentido de corresponsabilidad, la escasa predisposición al financiamiento de los acreedores internacionales (Rapoport, 2020b).

La apuesta por revisar la deuda externa se materializó en la política nacional en la sanción de la ley N. 23.854, que rechazó las cuentas de inversión para los años 1976-1983, la suspensión por seis meses del pago de las acreencias a los bancos comerciales y la creación de la Comisión Investigadora de Actos Ilícitos en el Senado de la Nación (Manzo, 2011). Esta Comisión, que en verdad significaba cierta continuidad con el juicio iniciado por Alejandro Olmos sobre la deuda externa en 1982, tuvo la tarea de allanar el estudio jurídico del secretario de coordinación y programación de la deuda durante el gobierno militar, Guillermo Klein. En la misma línea y desde el BCRA se creó en julio del mismo año un cuerpo de contadores para examinar la deuda privada en moneda extranjera fiscalizada en 17 mil millones de dólares. En aquel entonces el BCRA carecía de los registros contables sobre la deuda como de los avales otorgados por el sector público a agentes privados en operaciones de créditos internacionales (Olmos, 2006).

7 Ídem.

8 Grinspun Bernardo, Discurso pronunciado por Cadena Nacional de Radio y Televisión. 19 de Julio de 1984. Centro de Documentación e Información, Ministerio de Economía, Buenos Aires, p. 6.

9 El primer antecedente fue la reunión en Quito, Ecuador, de países de Latino América y América Central en enero de 1984 para discutir las consecuencias de la crisis económica internacional. Sin embargo, la cuestión de la deuda se había tornado una referencia obligada. Luego de una intensa participación por parte del canciller argentino Dante Caputo, se realizó la reunión en el mes de junio de 1984 en Cartagena, Colombia, con la participación, además de ese país, de Bolivia, Brasil, Ecuador, México, Perú, República Dominicana, Venezuela, Uruguay y Argentina. 
Alfonsín, en esta misma línea, ya había declarado en 1983 que se iba a determinar qué parte de la deuda era legítima y la negociación de los pagos se haría según las capacidades del país, recurriendo oportunamente a los organismos internacionales como a la banca acreedora, aunque rechazando recetas recesivas y ortodoxas. De esta forma, Alfonsín (1983) diría, "presentamos nuestro programa [...] compatible con el crecimiento del país y el pago de la deuda y a ese programa nos vamos a tener. Seremos flexibles en las formas, pero no en el contenido" (61). Incluso, al respecto, el Canciller Dante Caputo dijo en Ecuador durante la sesión inaugural de la Conferencia Económica Latinoamericana (1984) que:

\begin{abstract}
"La democracia argentina no acepta la trampa en la que el sistema financiero internacional y las minorías a él asociados la han colocado al generar esta agobiante deuda externa [...] La crisis que sufrimos quizás tenga como contrapartida la creación de una oportunidad invalorable para convertir finalmente en realidad la integración en América Latina y el Caribe". ${ }^{10}$ (Como se cita en Díaz: 2008, 120).
\end{abstract}

Luego, el planteamiento de Cartagena exigía la corresponsabilidad entre deudores y acreedores, reafirmaba la voluntad de cumplimiento en los pagos, abría un diálogo político sobre el problema de la deuda, exigía el tratamiento conjunto de la misma y la simetría del ajuste (Navarrete, 1985; O’Connell, 1988). En particular, se planteó la reducción de las tasas de interés, un financiamiento compensatorio a razón de las mismas, la modificación de las rigideces bancarias en los países acreedores, un mayor volumen crediticio por parte de los organismos financieros multilaterales y un mejoramiento de las condiciones del comercio internacional:

\begin{abstract}
"Medidas que conduzcan a la rápida e inmediata reducción de las tasas nominales [...] que en las negociaciones y operaciones de nuevos créditos la banca internacional utilice tasas de preferencia [...] la abolición de los intereses de mora [...] extensión de los plazos de pago [...] no se deben comprometer los ingresos provenientes de las exportaciones [...] la reactivación de las corrientes crediticias hacia los países deudores [...] la revisión de los criterios de condicionalidad del Fondo Monetario Internacional (dando prioridad al) crecimiento de la producción y el empleo [...] el establecimiento de las metas fiscales y de la balanza de pagos [...] deberán excluir el efecto de la elevación de las tasas de interés internacionales [y] la modificación de las metas monetarias acordadas deberá efectuarse para prever alzas imprevistas en la tasa de inflación". ${ }^{11}$
\end{abstract}

Como señalaron Bouzas y Keifman (1988) cuando el gobierno argentino anunció la suspensión temporal de los pagos y no afectar sus reservas para cancelar los intereses atrasados inmediatamente el Eximbank anunció el cierre de créditos para la Argentina. El episodio terminó en el acuerdo de un préstamo puente el 31 de marzo de 1984 entre varios gobiernos latinoamericanos, EE. UU y la banca acreedora por 400 millones de dólares para evitar la mora argentina. Así, la Argentina no utilizaba sus escuetas reservas, ${ }^{12}$ los deudores capitalizaban un acto de solidaridad y el gobierno norteamericano salvaba una fecha crítica de vencimiento.

En lo que sigue la Argentina presentó al FMI una carta formal en la que reclamaba la imposibilidad de efectuar los desembolsos y rechazaba medidas que impactaran en la reducción del salario real. Por su parte, el organismo argumentaba que era imposible estabilizar el presupuesto mientras los salarios se indexaban a la inflación pasada; de modo que el FMI ignoró el comunicado y los acreedores internacionales mostraron indiferencia ante el reclamo argentino. Los intereses de la deuda, de una insolvencia estructural, representaron un 5,1\% del PBI entre 1984-87 y para Machinea y Juan Sommer (1992) significaban "el principal problema económico" (70) aunque las transferencias y seguros de cambio del Estado a los sectores más concentrados del capital también constituían un problema.

Como afirman Ortíz y Schorr (2006) sostener esta doble fuga fue posible gracias a la reducción de la participación de los asalariados en el ingreso nacional, la cual los autores calculan en un 13\% del PBI para el periodo (80 mil millones de dólares). Las autoridades económicas que asumieron en 1983 no daban cuenta de este problema, o bien elegían no denunciarlo, pues en el

10 Discurso del canciller Caputo en La Conferencia de la Conferencia Económica Latino Americana, Quito, Ecuador. La Nación, 14 de enero de 1984, p. 2.

11 Consenso de Cartagena (1985) El Trimestre Económico, 205(52), 267-272.

12 Calculadas en 3.205 millones de dólares al momento de la asunción de 1983 (Rapoport, 2020). 
diagnóstico del BCRA de 1984 se aseguraba que los principales problemas eran el avance de la inflación, los efectos de la recesión en los ingresos de la población, la caída de la inversión y el endeudamiento público:

\begin{abstract}
"La economía argentina ha estado signada en los últimos años por tres características básicas, que han contribuido a crear el actual estado de la situación. En primer lugar, una alta tasa de inflación: mientras que hasta 1974 los índices inflacionarios sólo habían superado el $100 \%$ en el año 1959, a partir de 1975 nunca estuvieron por debajo de ese porcentaje, con la sola excepción de del incremento de los precios mayoristas en 1980 que fue del 75,4\%. En segundo lugar, la economía registró una tendencia persistencia a caer en situaciones recesivas: mientras en los veinticinco años anteriores a 1975 el producto bruto interno (PBI) mostró caídas sólo en cuatro ocasiones [y ninguna de ellas en los diez años posteriores a 1975], en el periodo de 9 años que va de 1975 a 1983 fue menor al de 1970 y se produjeron significativas reducciones en las remuneraciones reales de vastos sectores de la población, derivadas de la caída de los salarios reales y del incremento de la tasa agregada de desempleo y subempleo del factor trabajo. Similar fue el comportamiento de la inversión, hecho de significativa trascendencia, debido a que su evolución condiciona el desarrollo de la economía en el largo plazo. Por último, la deuda externa argentina que a fines de 1975 era de 7.875 millones de dólares, superaba ligeramente los 45.000 millones de dólares en 1983 [...] la deuda externa que a fines de 1975 equivalía a algo menos de 3 veces las exportaciones de ese año, pasó a representar cerca de 6 veces las exportaciones de 1983. Los intereses anuales generados por el endeudamiento eran a fines de 1975 aproximadamente el $1 \%$ del producto bruto interno, el $4 \%$ del ahorro interno y el $16 \%$ de las exportaciones. En 1983 esas mismas relaciones alcanzaban alrededor del 8,0\%, 67\% y 70\%, respectivamente". ${ }^{13}$
\end{abstract}

Así, la inflación, la recesión y la deuda eran considerados tres pilares que en general compartía el gobierno para explicar la crisis económica ubicando su origen en los comienzos del régimen de 1976. Mientras tanto debía avanzarse en un contexto internacional hostil caracterizado por altas tasas de interés, la caída de los productos agropecuarios con consecuentes problemas para su colocación en mercados externos y una creciente presión de acreedores y organismos internacionales. Sin embargo, la postura de confrontación inicial con el FMI se fue volviendo acuerdista abandonando la promesa de revisión de la deuda como de ajustar los pagos a las posibilidades de la economía real y cediendo al pedido de los acreedores de negociar caso por caso con el organismo. Finalmente, en vez de seguir avanzando en que la justicia comprobara la existencia de operaciones de créditos bajo procedimientos fraudulentos el gobierno asumió la totalidad de la deuda heredada de la dictadura pagando lo que declaraban los acreedores. ${ }^{14}$

\title{
4.LAS CONDICIONES ECONÓMICAS DEL PLAN GRINSPUN
}

Como lo relata Brenta (2014), entre las recomendaciones del representante argentino Presbich y la presión de García Vázquez, se llegó a un acuerdo con el FMI. El organismo aceptó la indexación salarial aclamada por Grinspun al costo de endurecer la política fiscal y monetaria con una depreciación sustancial del tipo de cambio real. Grinspun firmó la nueva carta en septiembre, pero el FMI volvió a objetar que los aumentos salariales del 14\% mensual eran excesivos. Ante la falta de acuerdos y como estrategia para evitar el default argentino y la pérdida de credibilidad ante los acreedores, el organismo reunió los fondos que la Argentina necesitaría para 1985 (unos 8 mil millones de dólares) mediante un préstamo puente entre gobierno de EE. UU, algunos países industrializados, el BM, el Banco Interamericano de Desarrollo (BID), el Club de París, los bancos acreedores y el mismo FMI.

En el sector interno tanto Alfonsín como Grinspun tomaron como interlocutor a la UIA, pero el conflicto partidario que yacía en la UCR en tanto había posiciones diferenciadas sobre la política económica llevó a que otros ministros, especialmente Dante Caputo y el secretario de industria Carlos Lacerca comenzaran tratativas con otros empresarios a fin de acordar políticas para contener la inflación e incentivar la inversión. Así, los entonces miembros del reciente formado G9, una alianza informal de nueve grandes industrias desprendidas de la UIA y el Consejo Empresario

13 Banco Central de la República Argentina (30 de agosto de 1984) Memoria Anual. Cuadragésimo noveno ejercicio 1983. Buenos Aires, 3. 14 Luego, en el año 2000 la sentencia del juez Jorge Ballesteros dictamino que la deuda contraída entre 1976 y 1982 fue mediante mecanismos irregulares dando importantes argumentos para judicializar la misma. 
Argentino (CEA) que habían alcanzado significativas posiciones durante la dictadura comenzaron a tener un lugar en negociaciones informales con el gobierno. Estos grupos, aunque carecían de una estructura representativo en la democracia, poseían un inédito poder estructural que les permitía incidir en decisiones de inversión, cambios de cartera y disposición de cumplir obligaciones tributarias (Novaro, 2020). ${ }^{15}$

Por consiguiente, entre los acuerdos de precios realizados con la UIA y un conjunto de políticas fiscales y monetarias contractivas con el FMI se propuso reducir el 30\% de una inflación que alcanzaba un $627 \%$ para 1984 . Se implementó un control de precios permitiendo previamente algunos aumentos en el mes de septiembre para luego congelarlos e ir eliminando los controles. En materia fiscal el FMI entendía que con la inflación y la declinación de las inversiones privadas había aumentado el déficit público desde 1980. El mismo, que durante el cuarto trimestre de 1983 había alcanzado un 16, 5\% del PBI, se proyectó en un 8,5\% para fines de 1984 y 5,4\% para 1985, es decir, se proyectó reducirlo gradualmente. A esto debía sumarse que desde 1983 surgió un nuevo desequilibrio fiscal proveniente del BCRA que, al asumir con tasas de interés muy bajas, financiando operaciones antes cubiertas por el sector financiero, generó desequilibrios conocidos como déficit cuasi fiscal, consecuencia directa de uno de los pilares de la reforma financiera de 1977: la cuenta de regulación monetaria. Esta, compensaba los efectivos mínimos que por ley debían mantener las entidades financieras como respaldo de sus obligaciones buscando así neutralizar la expansión monetaria que significó la liberalización del sistema financiero y la inflación. Heredada de la dictadura como gran parte del déficit cuasi fiscal, la expansión monetaria calculada en unos 62 mil millones de pesos incentivaba la inflación (Basualdo, 2018) y comenzaba a ser una nueva variable de control por parte del FMI. El déficit operativo del BCRA, si se suman los intereses de los pasivos internacionales, fue calculado en 3,5\% del producto para diciembre de 1983. Para contrarrestar estos desequilibrios el Fondo exigía el aumento mensual de las tarifas públicas, la reducción de las transferencias a las empresas estatales y a las provincias y un congelamiento salarial (Brenta, 2014). No obstante, la negativa de Grinspun en avanzar en un plan de ajuste y la evolución macrosómica de la Argentina testeada por el FMI truncaron el acuerdo.

Como señalaron Pesce (2006) y Aruguete (2004), el argumento implícito de la gestión económica de Grinspun, era que se podía reeditar el modelo de sustitución de importaciones, con la excepción de que en el nuevo contexto se debía incluir una deficitaria balanza de pagos originada en el problema de la deuda externa. Esta argumentación asegura que se trataba de una "nostalgia" sobre el pasado desarrollista de los años de la presidencia de Arturo Ilia, así como cierto desconocimiento de la crisis que afectaba al Estado (Heredia, 2006). Pero en aquel entonces también Schvarzer (1987b) señaló que las políticas de tipo keynesiana habían sido inadecuadas al no tener en cuenta las profundas transformaciones desarrolladas con la desarticulación de la estructura productiva durante la dictadura. Es posible que también el apoyo de los sectores de izquierda en el alfonsinismo más sus promesas de bienestar y justicia social hayan influenciado para seguir una orientación económica radicalmente diferente a lo que se concebía como ajuste ortodoxo. En todo caso, las políticas de reactivación practicadas por el equipo económico de Grinspun no arrojaron los mismos resultados en circunstancias diferentes al pasado como el avance de una inflación de tres dígitos, la presión de nuevos grupos económicos consolidados durante la dictadura militar, una abultada deuda externa y las presiones distributivas de los trabajadores.

Sin embargo, a pesar de la falta de acuerdos con el Fondo, el Plan de Grinspun avanzó y las primeras medidas en la economía nacional se dirigieron a un aumento de los servicios y salarios industriales, el establecimiento de pautas para la variación futura de los precios y las tarifas públicas, un sistema de control de precios industriales, la determinación del tipo de cambio y la

15 En un principio estos grupos fueron identificados como "patria contratista". Nacidos durante la fase de sustitución de importaciones, eran un grupo de empresas que experimentaron un gran crecimiento gracias a la política de fomento y compras del Estado. Estos industriales compartían en general los postulados liberales de las grandes industrias como la política impositiva o laboral, aunque en materia de proteccionismo, el papel del Estado y el fomento del mercado interno se inclinaban más a las diatribas de las empresas pequeñas y medianas organizadas en la corriente interna Movimiento Industrial Nacional (MIN) de la UIA, desde donde provenían en un comienzo a principios de los ' 80 . Fue en los años 1990 cuando estos empresarios, que habían formado el G9 durante 1983 fuera denominado como "los capitanes de la industria" (Birle, 1997). 
reducción de las tasas de interés reguladas (Fanelli y Frenkel, 1986). También se apuntó a combatir el déficit fiscal con una mayor recaudación impositiva, un aumento de las tarifas públicas y una reducción y transferencia del gasto público. Este último fue reorientado hacia la educación y planes sociales tendientes a reducir la pobreza como el Plan Alimentario Nacional en detrimento de los cuantiosos gastos militares establecidos en dictadura (Damill y Frenkell, 1990).

También, el BCRA tomó algunas decisiones con García Vázquez al frente para morigerar los movimientos especulativos que tornaban de desordenado e ineficiente al sistema financiero, pero sin generar cambios sustanciales. Al respecto, se determinaba un mercado con tasas de interés reguladas:

\begin{abstract}
"A partir del mes de agosto, se decidió eliminar el segmento libre de préstamos y depósitos quedando en el sistema institucionalizado un único mercado con tasas de interés reguladas por el Banco Central. En ese nuevo contexto se permitió a las entidades aplicar sus recursos propios líquidos en operaciones de préstamos interfinancieros a tasa libre, en la tenencia de Bonos externos y en operaciones de préstamos con sus clientes con cláusulas de ajuste por inflación". ${ }^{16}$
\end{abstract}

Otra de las medidas instrumentadas para aplicar cierta regulación monetaria fue la utilización del efectivo mínimo que permitió a las entidades bancarias aliviar las condiciones de iliquidez en que se encontraba el sistema financiero; aunque tuvo como contraparte la cuenta de regulación monetaria y su incidencia en el déficit cuasifiscal. Así, el BCRA permitía "reducciones en el cargo punitorio aplicable y les permitió -en agosto y octubre- la reducción de una parte de las exigencias del efectivo mínimo a condición de su compensación el mes siguiente mediante una suba equivalente" ${ }^{17}$ Por su parte, también se trataba de contener el efecto multiplicador de la base monetaria que venía registrándose como producto de un sistema liberalizado que operaba con un reducido coeficiente de encaje legal. Así, mediante el incremento del encaje en el sistema, a excepción de los meses mencionados, se otorgaba cierta solvencia. También, para contrarrestar la caída de la demanda global de activos monetarios en pesos -arrastrando la oferta del crédito bancario total-, que las autoridades entendían sólo como una consecuencia de corto plazo causada por las expectativas devaluatorias recientes y tasas de interés negativas:

“[...] se dispuso reducir, en setiembre, el plazo mínimo de concertación para los depósitos a plazo fijo ajustables con índice de precios al consumidor, que pasó de 180 días a 120 días. Con la misma finalidad y la de brindar a los ahorristas una nueva alternativa de inversión en abril se habían creado los depósitos a plazo fijo ajustables con cláusula dólar estadounidense, con plazo mínimo en 90 días". ${ }^{18}$

Mientras se eliminó el segmento libre del mercado financiero en el mes de agosto, se ofreció a las entidades financieras un préstamo compensatorio y se determinó que con los recursos provenientes de la reducción del efectivo mínimo debía financiarse proyectos de inversión, producción, comercialización y servicios que requieran la demanda interna y las exportaciones aunque, a contracorriente, se siguieron autorizando las conversiones a pesos de deuda en moneda extranjera de productores agropecuarios y gobiernos provinciales lo que traería problemas entre las directivas en economía y el central. ${ }^{19}$

\title{
5.EXITOS PARCIALES ANTE PROBLEMAS ESTRUCTURALES O DE PUJAS INTER- CAPITALISTAS CONTRA EL ESTADO NACIONAL
}

Las políticas implementadas tuvieron algunos éxitos parciales hacia fines de 1984. El PBI aumentó un 2,6\%, mientras que el empleo, los salarios reales y el consumo también mostraron signos de reactivación.

15

16 Banco Central de la República Argentina (30 de agosto de 1984) Memoria Anual. Cuadragésimo noveno ejercicio 1983. Buenos Aires, p.

\footnotetext{
17 Ibidem, p. 18

18 Ibidem, p. 20

19 Ibidem, p. 25-31
} 
Gráfico 1

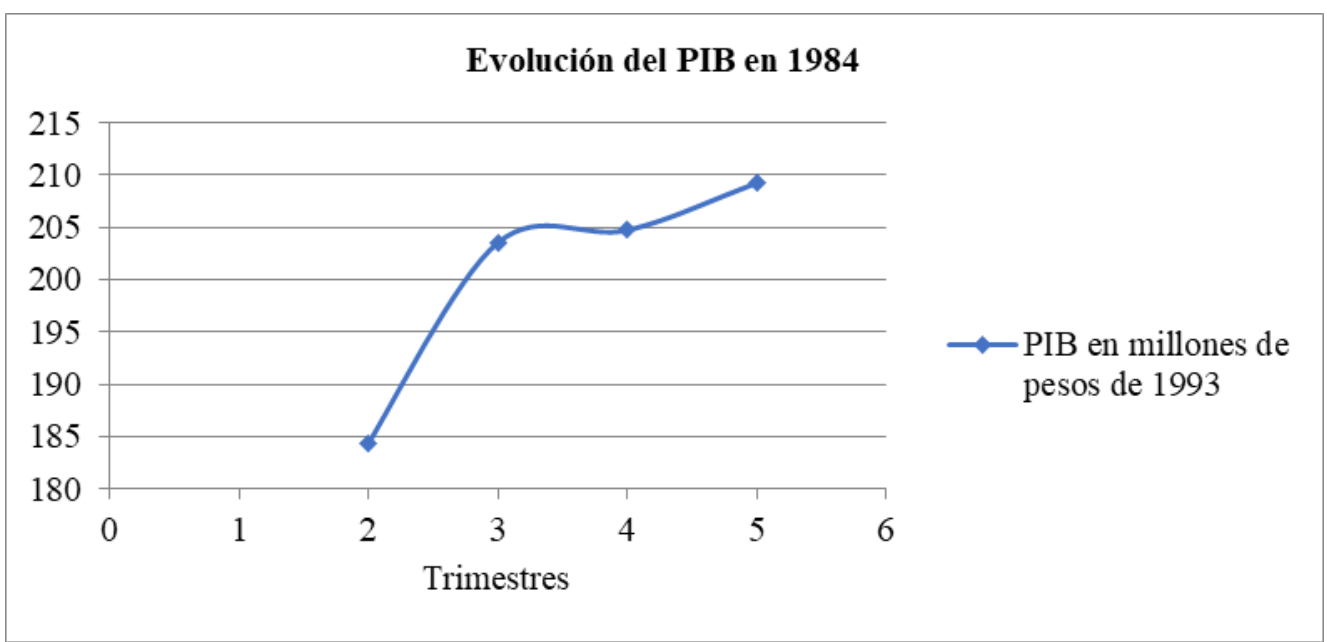

Fuente: elaboración propia en base a datos consultados en Santilli (2020) e Instituto Nacional de Estadística y Censos. Estadísticas Históricas: Producto Interno Bruto a precios de mercado y Valor Agregado Bruto, por sector económico, a precios básicos. En millones de pesos, a precios de 1993.

\section{Gráfico 2}

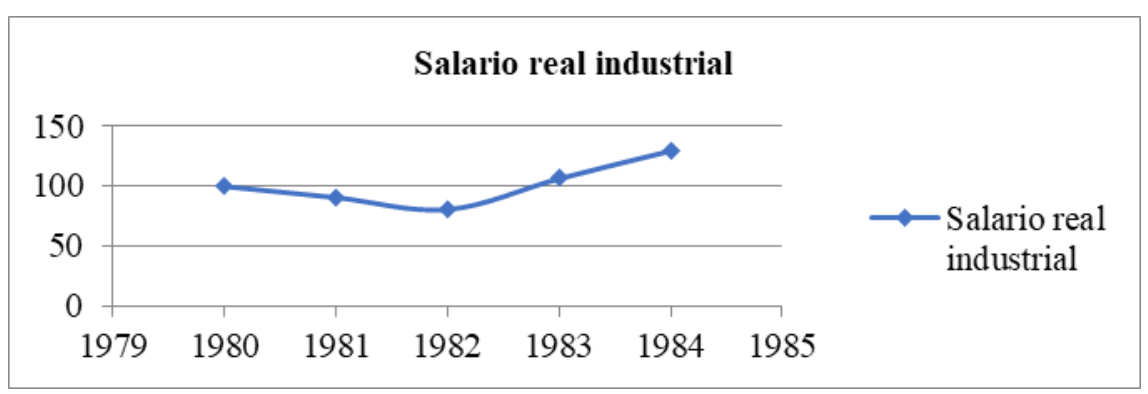

Fuente: elaboración propia en base a datos presentados en Rapoport (2020).

La anunciada reorientación del gasto se llevó a cabo y lo destinado a servicios sociales aumentó significativamente (de un 19,5\% en 1983 paso a un 32,3\% en 1984). También, se logró un balance comercial positivo, a pesar del deterioro de los términos de intercambio que caracterizaron prácticamente toda la década. Sin embargo, el déficit fiscal se mantuvo en 10.4 puntos del PBI para 1984 (Rapoport, 2020) y, como se puede apreciar en el grafico 5 la inflación no cedía desde la asunción presidencial mostrando una tendencia más pronunciada al alza desde agosto.

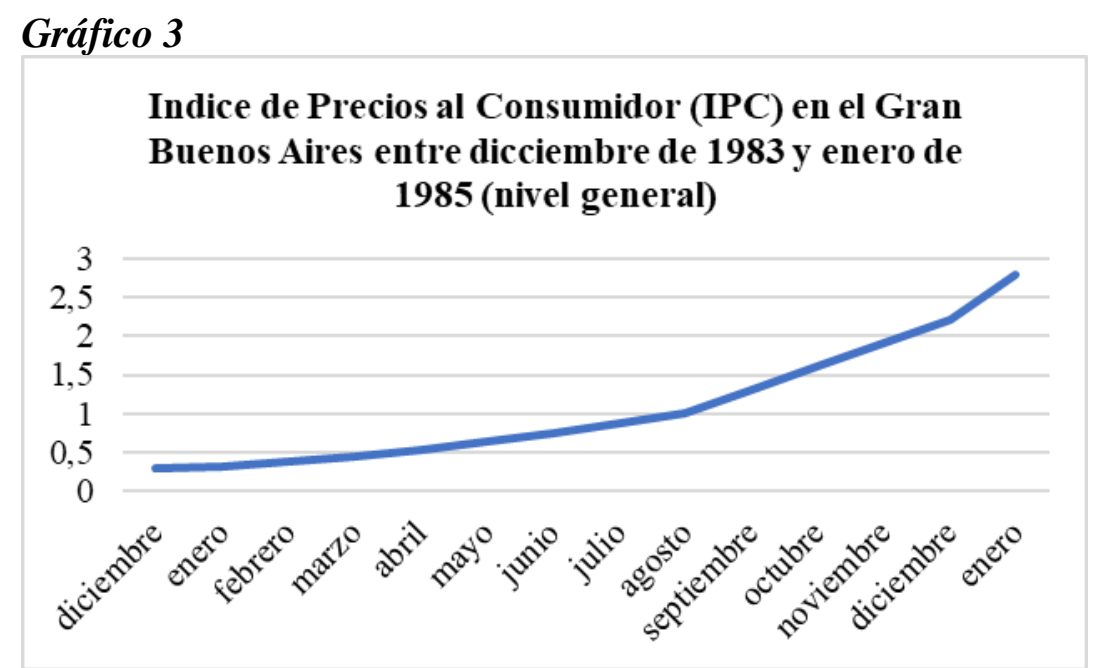


Fuente: elaboración propia en base a datos presentados por el Instituto Nacional de Estadísticas y Censos (INDEC)Series Históricas.

De esta forma, se hacía visible que la política inicial del gobierno democrático no atacaba ninguno de los problemas estructurales que tenía la economía argentina (Heymann, 1986). El fracaso de la renegociación de la deuda externa en los términos que la planteaba el equipo económico, la caída de la inversión bruta fija, el deterioro de las cuentas públicas y de los salarios se combinaron para tornar un contexto socioeconómico negativo. ${ }^{20}$ Los problemas estructurales que mostraba la economía como la inflación y los déficits persistían, evidenciando que la crisis fiscal era más intensa de lo que se suponía y que la inflación se transformaba en una variable casi imposible de controlar, pues los precios al consumidor habían incrementado en el transcurso del año 1984 más del 600\% erosionando tanto la recaudación del sector público como los esfuerzos por reducir el gasto (Damill y Frenkel, 1990).

La estructura empresarial había cambiado durante la última dictadura y los nuevos grupos económicos operaban de forma conglomerada integrada y diversificada aprovechando la inserción multi-implantada y la transnacionalización para maximizar sus ganancias y ganar creciente autonomía frente al accionar estatal y al propio desenvolvimiento de la economía nacional (Basualdo, 2018). Los núcleos centrales del nuevo poder económico que habían internalizado los sobreprecios asociados a la provisión de insumos estratégicos al estado; los subsidios implícitos en la promoción industrial regional y sectorial y las ganancias por valorización financiera derivadas del sistema de incentivos inherente al programa de Martínez de Hoz entre 1978 y 1981, se habían expandido patrimonialmente de modo sustantivo y presionaron por sus intereses: mayor pago de los servicios de la deuda (para los ligados al capital financiero internacional), incremento de precios según la inflación esperada, la protección de sus divisas hacia plazas más seguras y la continuidad de los privilegios que recibían a través de la acción estatal para mantener los niveles de inversión y/o acrecentarlos.

El gobierno no atinó a detener la sangría de recursos fiscales orientados a afianzar al capital concentrado mediante los diversos regímenes de promoción industrial y sectorial, como mediante el seguro de cambio implementado para la deuda privada, ambos durante la dictadura, desde el BCRA. Esto imposibilitaba el cumplimiento de las metas fiscales necesarias para mantener un mínimo acuerdo con los acreedores extranjeros en relación al pago de la deuda. En el fondo de estas cuestiones se encontraban las diferencias entre Grinspun y García Vázquez, quien tras asumir en el BCRA no reemplazó a la planta mayor gerencial del banco confirmando en sus cargos a exfuncionarios de la dictadura que habían participado en la reforma financiera de 1977 y la estatización de la deuda privada, entre otras políticas, como Pedro Camilo López, Elías Salama, Daniel de Pablo, René De Paul, Jorge Rodríguez y Enrique Bour; durante la gestión del discípulo de Milton Friedman Adolfo Diz (1976-1981). Mas concretamente, esto trabó las iniciativas de Grinspun por reducir las tasas de interés, generar créditos accesibles y alargar los plazos de los mismos que eran constantemente exigido por Grinspun. Por el contrario, el BCRA mantuvo gran parte de su política anterior, especialmente el financiamiento del déficit fiscal legado por la dictadura mediante adelantos del Banco como parte del funcionamiento de la Cuenta de Regulación Monetaria.

En un cuadro general y como fruto del evidente fracaso económico, durante una visita de Alfonsín a EE. UU en septiembre de 1984 se anunciaría un "giro realista" en las relaciones con la potencia (Cisneros y Escudé, 2000: 168). Esto significaba que el gobierno, de la mano de su Ministro de Relaciones Exteriores Dante Caputo, cambiaba su política inicial de acercamiento a países socialdemócratas europeos y crítica a EE. UU en torno a la cuestión de América Central y la deuda latinoamericana. Por el contrario, aunque los vínculos con las naciones europeas no se detuvieron, a partir de aquel entonces la llamada relación madura con EE. UU buscaba el

20 Con respecto al déficit fiscal, éste había bajado casi 3 puntos del PBI, pero a raíz de una caída del gasto y no de una mayor recaudación como se esperaba. La inflación inercial existente hacía que se tornara temporalmente insignificante dicha baja. 
entendimiento sin alinearse a los preceptos de la potencia, pero abandonando, por ejemplo, los reclamos de una deuda ilegítima.

\section{NI ORTODOXIA NI HETERODOXIA: AVANCE DE LA INFLACIÓN}

Ante el fracaso del Plan Grinspun frente a la creciente presión de los acreedores externos, la Reserva Federal de EE. UU y la persistencia de la inflación, el equipo económico cambió la estrategia confrontativa. Durante la segunda mitad de 1984 se envió una carta al FMI retractándose de la posición inicial y expresando la voluntad de acordar un plan de ajuste. En diciembre de 1984 se llegó a un acuerdo Stand-By, esta vez delineado por el organismo, en el que se asumía el cambio de rumbo económico por parte del gobierno argentino y el equipo oficial. El préstamo aprobado fue de 1.419 millones de dólares, un préstamo compensatorio por caídas de las exportaciones por 270 millones de dólares y un conjunto de políticas contenidas en este programa se aglutinaba en un aumento de las tarifas de servicios públicos y del tipo de cambio, reducción del déficit fiscal y contracción monetaria (Machinea y Sommer, 1992).

Hasta el mes de diciembre de 1984, a pesar de la desconfianza de los 320 bancos acreedores en la capacidad de cumplimiento de las metas, se efectuaron los desembolsos. No obstante, al poco tiempo se hizo evidente que los resultados de la política económica no se ajustaban a lo pautado, pues, los aumentos en las tarifas públicas inmediatamente desembocaron en alzas en el resto de los precios provocando una ola inflacionaria. Lo mismo ocurría con la devaluación de la moneda que, acompañada de la restricción monetaria y la liberalización del sistema financiero, producían un alza brutal de las tasas nominales de interés que terminaban retroalimentando la inercia inflacionaria (Gerchunoff y Llach, 2019).

En este contexto la actividad productiva cayó severamente y comenzó a revelarse que el ajuste ortodoxo tradicional que imponía el FMI no daba resultados ante un sistema de precios tan volátil como al que había llegado la Argentina (Heymann, 1986). El acuerdo terminó provocando más inflación y recesión, evidenciando la institucionalización de un régimen de alta inflación y consolidando un déficit cuasi fiscal desatado por una emisión monetaria que buscaba financiarse con la imposición de altos encajes y depósitos disponibles en el sistema financiero remunerados por el BCRA. Así, la inversión pública y privada continuó siendo la principal variable del ajuste, de modo que la caída de la inversión global, que había sido del 11\% del PBI en 1980, para 1985 llegaría al 23\% (Damill y Frenkel 1990).

Grinspun no solo se enfrentó la oposición de los acreedores, sino también a los sindicatos, que a partir de la Ley de Reordenamiento Sindical del Ministro de Trabajo Antonio Mucci se convirtieron en férreos opositores al gobierno. Esta, tenía como objetivo democratizar los sindicatos, con escasos resortes democráticos luego del periodo dictatorial (Birle, 1993), proponiendo el voto directo, la representación de las minorías y elecciones inmediatas sin proscripciones en todos los niveles bajo control oficial. La ley se encontró con la mayoritaria oposición de los Senadores peronistas y constituyó un primer fracaso del gobierno con el sector a su política económica. A partir de entonces, el gobierno cambió la estrategia política confrontativa con los sindicatos buscando desarrollar instancias que de acuerdos sectoriales.

Durante junio y agosto se firmó el Acta de Coincidencias entre las fuerzas políticas destinada a poner de común acuerdo la defensa de la democracia, la cuestión de Malvinas y aún de la deuda externa. Luego se generó una instancia llamada la Concertación Económica y Social con representantes del gobierno, los sectores laborales y empresarios, pero, finalmente, la CGT abandonó la mesa generándose una oposición más dura del sindicalismo. Posteriormente se produjo una singular alianza entre empresarios y la CGT, quienes firmarían el Documento de los 20 puntos donde se exigía un redimensionamiento del Estado empresario y cambios en las políticas cambiarias y arancelarias (Pesce, 2006). Así, se hizo evidente que el alfonsinismo no logró ni disciplinar a los 
sindicatos, por un lado, ni incluirlos posteriormente en el espacio definido por la democracia alfonsinista (Barros, 2002).

La ley Mucci fue un experimento para la UCR en tanto radicales como peronistas a partir de aquel episodio reformularon sus estrategias políticas futuras. Como dicen De Riz y Smulovitz (1990), la minoría de la UCR en el senado se traducía en, sin un pacto formal que legitimara las relaciones entre la Nación y las Provincias, un espacio de lucha entre representantes provinciales por conseguir una cuota de la riqueza nacional. Para el gobierno el fracaso del proyecto de ley determinó que las decisiones conflictivas como las que involucraban a la política económica se tomaran fuera del ámbito legislativo o en casos de falta de acuerdos fueran demoradas. Por su parte, para el Partido Justicialista (PJ) la experiencia significó el reconocimiento de que como oposición tenían la capacidad de aglutinar sus fuerzas. Como dijo Canitrot (1992) a los problemas del gobierno democrático con las corporaciones militares se sumaron las difíciles relaciones con las corporaciones sindicales y condicionaran la política económica del gobierno en toda la etapa.

También dentro de su partido crecía el descontento de funcionarios como el Canciller Caputo y de quien sería titular del BCRA a partir de febrero de 1985, Alfredo Concepción, que manifestaban las contradicciones entre los funcionarios más tradicionales y los que proponían una estrategia acuerdista (Morresi, 2008). Esto era un reflejo de las líneas partidarias de la UCR que se reacomodaban de acuerdo a los vaivenes políticos y económicos de una coyuntura que se tornaba cada vez más difícil. En este sentido, la muerte de Raúl Borrás en mayo de 1985, la de Roque Carranza en febrero de 1986 y el posterior alejamiento y muerte de Germán López en 1989, contribuyeron a desarticular la estrategia inicial asentada en cuadros procedentes de la estructura partidaria, especialmente de los que se identificaron con el Movimiento de Renovación y Cambio (De Riz y Feldman, 1991).

Falto de apoyos, el poder concentrado de los conglomerados económicos locales y extranjeros que habían ganado posiciones en la dictadura mostró un escaso interés en el plan Grinspun, pues la propuesta mercado internista ya no resultaba funcional a sus intereses. Los salarios habían dejado de ser un componente clave de la demanda agregada (Basualdo, 2018), más bien eran costos que debían ser reducidos para incrementar la competencia exportadora de un reducido número de productos con escaso valor agregado; pero en aquel entonces tenía sentido dado la afiliación del equipo económico como la inclinación inicial de Alfonsín de reactivar la producción y el salario real. Por otro lado, los rendimientos de la inversión que practicaban estos sectores eran canalizados hacia la fuga de capitales más que hacia el sector productivo de implicaba que tampoco una política crediticia de reactivación productiva surtiría efectos positivos. A su vez, los controles de precios que imponía la política de Grinspun eran fácilmente eludibles para sectores con dominancia económica en los mercados de actuación caracterizados por estructuras oligopólicas en las cuales incidían en la fijación de precios. Finalmente, fue el propio gobierno de Alfonsín el que terminó por oponerse al Plan Grinspun, colocando opositores a su política en sectores clave de la administración.

Incluso antes de que la gestión del ministro Grinspun finalizara, Alfonsín ya había comprendido que un proyecto de país moderno no se sostendría sobre una reactivación del consumo sino sobre un plan más complejo coordinado con los organismos internacionales y aquellos actores económicos fortalecidos durante la dictadura que se habían vuelto imprescindibles para el devenir del país y con los que si se quería controlar los precios debía acordarse. Podríamos decir que durante el plan Grinspun no hubo una completa coordinación entre las tareas de construcción de un nuevo régimen, relegadas ante la crisis, y la política económica, en tanto la confrontación y el desinterés por acordar con los nuevos actores de poder económico y financiero no lo permitían. Aunque también existía cierto optimismo en que la llegada al poder de un gobierno democrático y rupturista con el pasado reciente permitiría barrer a los viejos actores como el sindicalismo peronista, la corporación militar y los empresarios como lo había hecho en la estructura partidaria. 


\section{RESULTADOS}

La transición democrática argentina se enfrentaba no solo al contexto de la crisis de la deuda latinoamericana, sino a una profunda crisis propiciada por los cambios introducidos en el sistema económico por la dictadura precedente en el orden comercial, financiero y productivo. La raíz ideológica del primer ministro económico de Alfonsín, Grinspun, influyó en el diseño del primer programa económico de carácter keynesiano y con cierto anclaje en el pasado. A pesar de las confrontaciones con los actores internacionales y de un fuerte discurso contra los poderes locales, finalmente el gobierno debió ceder al FMI ante el avance de la inflación como manifestación principal de la crisis. El fracaso del plan Girnspun en sus variables, tuvo el trasfondo del creciente aislamiento del alfonsinismo y la UCR frente a la falta de concertación con el poder gremial, económico nacional, de la oposición política e incluso frente a las disputas al interior de su partidario. A pesar de los éxitos parciales en materia económica, los principales índices como el déficit público y la inflación no cedían, y daban cuenta de que se requerían cambios más profundos. $\mathrm{Al}$ ceder frente a los organismos internacionales y no modificar los resortes del poder concentrado local, el gobierno quedó sin espacios para desarrollar una política económica consistente y cedió espacios progresivamente a la aceptación de cánones ortodoxos como el control fiscal, la restricción monetaria y una progresiva integración comercial que preanunciaban el inicio de una nueva era.

\section{CONCLUSIONES}

Los estudios de los planes económicos como de la política económica argentina en el periodo reciente han sido abordados mayormente por economistas, sociólogos y otros cientistas sociales. Los historiadores vienen indagando hace algunos años, especialmente en problemas enmarcados en la última dictadura militar y la transición democrática, pero en el área de la historia económica son menores los esfuerzos. Creemos que la interpretación que hacemos de las discusiones económicas y políticas que hemos delimitado pueden contribuir a dar un marco explicativo del plan económico del gobierno alfonsinista, aunque también podían servir como insumo para el análisis y la interpretación histórica de exámenes de periodos posteriores a 1985. Especialmente, nos referimos a atender a las pujas partidarias dentro del radicalismo, a la injerencia de los actores de poder en las decisiones del gobierno como a la importancia de los componentes ideológicos en la legitimación de las políticas neoliberales, menos abordado en este trabajo. Por otro lado, la propuesta quizás también contribuya a iluminar futuros análisis que propongan estudiar la historia económica relacionándola, a su vez, al desafío de la construcción de un nuevo régimen político que encaró el alfonsinismo en aquellos años, aunque, según nuestra visión, haya quedado encerrado con escasas concertaciones limitándose a procedimientos democráticos formales frente al avance de la crisis económica.

Sin embargo, también es importante señalar que las limitaciones de una propuesta como la que hemos desplegado que, aunque puede constituir un punto de partida, se podrían subsanar en estudios posteriores con un mayor caudal de fuentes primarias como por ejemplo las memorias del BCRA, los informes presupuestarios del Estado, las plataformas electorales, entre otras; y la inclusión de otros actores políticos en el análisis. Por ejemplo, el rol de las provincias, de otros organismos internacionales y el papel de Norteamérica (incluyendo las pujas entre el Tesoro, la Reserva Federal y el FMI en cuestiones referidas a Latinoamérica) en términos de relaciones internacionales. No obstante, y como hemos mencionado, este puede ser un punto de partida para que la historiografía comience a revisar con un sentido interdisciplinar que la caracteriza cómo las elites políticas y económicas se adecuan a los nuevos contextos y coyunturas políticas, de sus pujas internas, del papel del pasado en sus prácticas, sus relaciones con otros actores y qué incidencia tiene esto finalmente en los planes económicos. En este sentido, esperamos haber contribuido con un incipiente aliciente a otras revisiones de los planes económicos en la inmediata postdictadura. 


\section{REFERENCIAS BIBLIOGRÁFICAS}

Acuña, C. y Golbert, L. (1990) Empresarios y política ¿Qué paso con el Plan Austral? Boletín Informativo Techint, N.263, 34-52.

Alfonsín, R. (1983) Discurso ante la Asamblea Legislativa el 10 de diciembre de 1983. En Garcete, H. y Yankelevich, N. (2018) Raúl Alfonsín por Raúl Alfonsín: discursos presidenciales ante la asamblea legislativa 1983-1989 (25-95). Buenos Aires: UBA.

Angenot, M. (2010) El discurso social. Los límites de lo pensable y lo decible. Buenos Aires: Siglo XXI.

Aronskind, R. (2008) Controversias y debates en el pensamiento económico argentina. Buenos Aires: UNGS.

Aruguete, E. (2006) Lucha política y conflicto de clases en la posdictadura. Límites a la constitución de alianzas policlasistas durante la administración de Alfonsín. Los años de Alfonsín. En Pucciarelli, A. (Coord.) Los años de Alfonsín ¿El poder de la democracia o la democracia del poder? (321-349). Buenos Aires: Siglo XXI.

Azpiazu, D. (1991) Programas de ajuste en la Argentina en los años ochenta: década perdida o decenio regresivo. Ponencia presentada en el seminario Ajuste económico, sindicalismo y transición política en los años ochenta, organizado por el Memorial de América Latina, San Pablo, 5 al 7 de marzo. http://publicacioneseconomia.flacso.org.ar/im ages/pdf/41.pdf

Azpiazu, D. y Nochteff, H. (1996) El desarrollo ausente. Buenos Aires: Norma.

Azpiazu, D.; Basualdo, E. y Khavisse, M. (2004) El nuevo poder económico en la Argentina de los 80. Buenos Aires: Siglo XXI.

Barón Lajer, A. (2018) Reforma y contrareforma 19761991: de la liberalización a la crisis del sistema financiero. En: Rougier, M. y Sember, F. (Coords.) Historia necesaria del Banco Central de la República Argentina. Entre la búsqueda de la estabilidad y la promoción del desarrollo (315-369). Buenos Aires: Lenguaje Claro.

Barros, S. (2002) Orden, democracia y estabilidad. Discurso y política en la Argentina entre 1976 y 1991. Córdoba: Alción.

Basualdo, E. (2018) Endeudar y fugar. Un análisis de la historia económica argentina, de Martínez de hoz a Macri. Buenos Aires: Siglo XXI.
Belini, C. y Korol, J. C. (2020) Historia económica de la argentina en los siglos XX y XXI. Buenos Aies: Siglo XXI.

Beltrán, G. (2006) Acción empresaria e ideología. La génesis de las reformas estructurales. En Pucciarelli, A. (Coord.) Los años de Alfonsín ¿El poder de la democracia o la democracia del poder? (199-243). Siglo XXI: Buenos Aires.

Birle, P. (1997) Los empresarios y la democracia en la Argentina. Conflictos y coincidencias. Buenos Aires: Editorial de Belgrano.

Bonnet, A. y Piva, A. (2019) El modo de acumulación en la Argentina contemporánea. Buenos Aires: Imago Mundi.

Bourdieu, P. (1985) ¿Qué significa hablar? Economía de los intercambios lingüísticos. Madrid: Akal.

Bouzas, R. y Keifman, S. (1988) Las negociaciones financieras externas de la Argentina en el periodo 1982-1987. En Bouzas, R. (ed.) Entre la heterodoxia y el ajuste. Negociaciones financieras externas de América Latina (198287) (27-81). Buenos Aires: Grupo Editor Latinoamericano.

Boyer, R. y Neffa, J. (2004) La economía argentina y su crisis (1976-2001): visiones regulacionistas e institucionalistas. Madrid: Miño y Dávila.

Brenta, N. (2014) Historia de las relaciones entre Argentina y el FMI. Buenos Ares: EUDEBA.

Canitrot A. (1992) La macroeconomía de la inestabilidad. Argentina en los '80. Boletín informativo Techint. $\mathrm{N}^{\circ} 272$. Buenos Aires.

Castellani, A. (2006) Estado, empresas y empresarios. La relación entre intervención económica estatal, difusión de ámbitos privilegiados de acumulación y desempeño de las grandes firmas privadas. Argentina 1966-1989. (Tesis de Doctorado), Universidad de Buenos Aires: FCS, Buenos Aires.

Damill, M., Fanelli, J.M., Frenkel, R. y Rozenwurcel, G. (1989) Déficit fiscal, deuda externa $y$ desequilibrio financiero. Buenos Aires: CEDES/Editorial Tesis.

Damill, M. y Frenkel, R. (1990) Malos tiempos. La economía argentina en la década de los ochenta. Buenos Aires. CEDES.

De Riz, L. y Smulovitz, R. (1990) Instituciones y dinámica política. El presidencialismo argentino. CEDES/37: Buenos Aires. 
De Riz, L. y Feldman, J. (1991) El partido en el gobierno: la experiencia en el radicalismo 1983-1989. Buenos Aires: CEDES, N. 64.

Síaz Alejandro, Carlos (1975) Ensayos sobre la historia económica argentina. Buenos Aires: Amorrortu.

Dornbusch, R. y Simonsen, M. (1987) Estabilización de la inflación con el apoyo de una política de ingresos. El Trimestre Económico, 54(214) 225-282.

Escudé, C. y Cisneros, A. (2000) Historia de las relaciones exteriores argentinas. Buenos Aires: CARI.

Fairclough, N. y Wodak, R. (2000) Análisis crítico del discurso. Van Dijk, T. (ed.) Estudios sobre el discurso. Una introducción multidisciplinaria (367-404). Barcelona: Gedisa.

Fair, Hernán (2013) El desvanecimiento del discurso nacional-popular en la Argentina (1988-1993) Entramado, 9(2), 118-137. https://revistas.unilibre.edu.co/index.php/entra mado/article/view/3467

Fanelli, J. y Frenkel, R. (1986) Deuda externa, ajuste y políticas de estabilización en Argentina. Notas sobre el Plan Austral. Estudios Económicos, Numero extraordinario: Programas heterodoxos de estabilización, 39-89.

Frenkel, R. y Fanelli, J. M. (1986) Del ajuste caótico al Plan Austral. Buenos Aires: CEDES.

Gerchunoff, P. y Llach, L. (2019) El ciclo de la ilusión $y$ el desencanto: un siglo de políticas económicas argentinas de 1880 a nuestros días. Buenos Aires: Critica.

Heredia, M. (2006) La demarcación de la frontera entre economía y política en democracia. Actores y controversias en torno de la política económica de Alfonsín. En Pucciarelli, A. (Comp.) Los años de Alfonsín ¿El poder de la democracia o la democracia del poder? (101150). Buenos Aires: Siglo XXI.

Heymann, D. (1986a) Tres ensayos sobre inflación y políticas de estabilización. Estudios e informes de la Cepal, N.64.

Lewis, P. (1993) La crisis del capitalismo argentino. Buenos Aires: FCE.

Miotti E. L. (1991), Acumulación, regulación y crisis en Argentina (Tesis doctoral inédita) Universidad de París, París: Francia.

Machinea, J. y Sommer, J. (1992) El manejo de la deuda externa en condiciones de crisis en la balanza de pagos: la moratoria argentina 198889. En Altimir, O. y Devlin, R. (comp.) Moratoria de la deuda en América Latina. Experiencia de los países (). Santiago de Chile: CEPAL.

Manzo, A. (2011) Estado y Derecho en la era de la globalización neoliberal: evolución del recetario neoliberal en Argentina. Revista
Direito e Praxis, 3(2), 2-41. DOI: 10.12957/dep.2011.2203

Morresi, Sergio (2008) La nueva derecha argentina. La democracia sin política. Los Polvorines: UNGS.

Muraca, M. (2007) Hegemonía y discurso p olítico en la Argentina, 1976-1985. En: Rinesi, E.; Nardacchione, G. y Vommaro, G. (Eds.) Los lentes de Víctor Hugo. Transformaciones políticas y desafíos teóricicos en la Argentina reciente (23-46). Buenos Aires: UNGS.

Navarrete, J. (1985) Política exterior y negociación financiera internacional: la deuda externa y el Consenso de Cartagena. Revista de la CEPAL, 27,

7-27. https://repositorio.cepal.org/handle/11362/112 $\underline{31}$

Neffa, J. (1998) Modos de Regulación, Regímenes de Acumulación y su crisis en Argentina (1880 1996). Una contribución a su estudio desde la Teoría de la Regulación. Buenos Aires: EUDEBA.

Novaro, M. (2020) Dinero y poder. Las difíciles relaciones entre empresarios y políticos en la Argentina. Buenos Aires: Edasha.

O’Connell, A. (1988) La coordinación de los deudores latinoamericanos: el consenso de Cartagena y el grupo de los ocho. Estudios Internacionales, 373-385.

Olmos, A. (2006) Todo lo que usted quiso saber sobre la deuda externa y siempre se lo ocultaron, ¿quiénes y cómo la contrajeron? Buenos Aires: Continente.

Ortiz, R. y Schoor, M. (2006) La economía política del gobierno de Alfonsín: creciente subordinación al poder económico durante la década perdida. En Pucciarelli, A. (Coord.) Los años de Alfonsín ¿El poder de la democracia o la democracia del poder? (291-333). Buenos Aires: Siglo XXI.

Ossona, J. L. (1992) Empresarios, Estado y democracia en la Argentina (1983-1989). Cuadernos de Ciclos, 4, 3-55.

Panigo, D. y Zane, E. (2004) Una revisión de las crisis económicas argentinas desde la Teoría de la Regulación. En Boyer, R. y Neffa, J. (coords.) La economía argentina y su crisis (19762003): visiones institucionalistas $y$ regulacionistas (39-86). Buenos Aires: Miño y Dávila.

Pesce, J. (2006) Política y economía durante el primer año del gobierno de Alfonsín. La gestión del ministro Grinspun. En Pucciarelli, 1. (coord.) Los años de Alfonsín ¿el poder de la democracia o la democracia del poder? (122228). Buenos Aires: Siglo XXI.

Rapoport, M. (2020a) Historia económica, política y social de la Argentina (1880-2003). Buenos Aires: Critica. 
Rapoport, M. (2020b) Política internacional argentina. De la formación nacional hasta nuestros días. Buenos Aires: Capital Intelectual.

Rougier, M. y Odisio, J. (2017) “Argentina será industrial o no cumplirá sus destinos". Las ideas sobre el desarrollo nacional (19141980). Buenos Aires: Imago Mundi.
Schvarzer, J. (1987b) Promoción industrial. Una experiencia para revisar. El Bimestre Político y Económico, 6to trimestre, 36, 5-8.

Schvarzer, J. (1987a) Restricciones a la política económica de la década del 80 en Argentina. El Bimestre Político y Económico, 32, 5-7.

Van Dijk, T. (1999) Ideología. Una aproximación multidisciplinaria. Barcelona: Gedisa. 